\title{
Improvement of Efficiency Prediction for a Kaplan Turbine with Advanced Turbulence Models
}

\author{
Dragica Jošt 1 , $^{*}$ - Aljaž Škerlavaj ${ }^{1}$ - Andrej Lipej ${ }^{1}$ \\ ${ }^{1}$ Turboinštitut, Slovenia
}

\begin{abstract}
A comparison between numerical simulations and measurements of a six-blade Kaplan turbine is presented in order to determine an appropriate numerical setup for accurate and reliable simulations of Kaplan turbines. Values of discharge, torque and losses obtained by different turbulence models are compared to each other and to the measurements. Steady state simulations with various turbulence models tend to predict large errors at full discharge rate, which are the result of underestimated torque on the shaft and overestimated flow energy losses in the draft tube. The results were slightly improved with the curvature correction (CC) and Kato-Launder (KL) limiter of turbulence production. Transient simulations were performed with shear-stress-transport (SST) turbulence model, the scale-adaptive-simulation (SAS) SST model, and with zonal large-eddy-simulation (ZLES). Details about turbulent structures in the draft tube are illustrated in order to explain the reasons for differences in flow energy losses obtained by different turbulence models. The effects of advection schemes and mesh refinement were tested. It was shown that all of the transient simulations considerably improved results at full discharge rate. The largest improvement was achieved with the SAS SST and the ZLES models in combination with the bounded central differential scheme. In addition, it was shown that the ZLES model produced accurate results at all operating points, with discrepancy lower than 1\%.
\end{abstract}

Keywords: water turbine, Kaplan turbine, efficiency prediction, CFD, turbulence models, ZLES

\section{INTRODUCTION}

For more than 20 years, computational fluid dynamics (CFD) has played an important role in the gradual improvement of the characteristics of axial water turbines. The relative effect of hydraulic shape modifications on the efficiency curve can be quite reliably predicted, yet the prediction of the absolute value of efficiency is still a challenge. The main problem is an inaccurate flow simulation in the draft tube. In this paper we present a case where extremely poor results of steady-state analysis were improved by transient simulations and advanced turbulence models.

A simulation of the Kaplan turbine is in general more time consuming than a simulation of the Francis turbine. The Kaplan turbine is double-regulated. Therefore, the overall efficiency curve is an envelope of partial efficiency curves, which are determined at a fixed angle of runner blades. The specifics of the Kaplan turbine are hub and tip clearance. At large guide vane openings there is often a clearance between overhanging guide vanes and the bottom ring. For accurate simulations it is recommended to take all such details into account. However, this results in large computational grids.

Often engineers have to make a compromise in order to reduce computational time. An extreme case is to simulate only one periodic segment of runner blades and a draft tube. In [1] it is reported that such an analysis was not satisfactory, until the effect of the spiral casing with stay and guide vane cascades on conditions at the runner inlet, were taken into account.
Another compromise is to perform steady-state simulations instead of transient ones. Flow in turbines is unsteady and usually a converged steady-state solution cannot be obtained [2]. Besides, two-equation Reynolds-averaged Navier Stokes (RANS) models, including the shear-stress-transport (SST) model that became a standard in turbomachinery, are not able to model all flow structures in the draft tube.

An important attempt to determine the applicability of state-of-the-art CFD simulations for a Kaplan draft tube was the Turbine 99 workshop held in Porjus, Sweden, in the years 1999, 2001 and 2005. The axial and swirl velocity components at the inlet (with rms-values and one Reynolds' stress component) and the pressure distribution around the outlet cross section were available before the workshop. For the third meeting, besides two inlet boundary conditions (the first one with a prescribed axi-symmetrical inlet velocity profile, and the second one with a measured phase-averaged resolved inlet velocity profile) also computational grids with 1 million and 2.5 million nodes with values for $\mathrm{y}^{+}$equal to 1 and 50 were provided by the organiser. Numerical results obtained by different CFD codes were compared to the experimental data for pressure recovery factor, pressure distributions along the draft tube walls and a detailed velocity field in one downstream cross section. One of the conclusions was that much attention must be paid to grid quality and boundary conditions [3]. Too coarse a grid and too high values of $\mathrm{y}^{+}$significantly reduced the accuracy of the pressure recovery factor. All tested RANS models predicted too weak a secondary flow [4]. Although the results 
of SST were significantly better than the results of the $k-\varepsilon$ model [5], they did not reach the same level of accuracy throughout the draft tube as the LES model. The best results were obtained by Kurosawa and Nakamura [6] using the dynamic Smagorinsky LES model and axi-symmetrical inlet boundary profile. Since 2005, several papers with the same draft tube using measured quantities from the Turbine 99 case, have been published [7] and [8]. In [7], the results obtained with the SST model, with time dependent angular resolved inlet velocity boundary condition on a mesh, with 6 million cells, were presented. The conclusion was that by using time dependent angular resolved inlet boundary conditions and grid refinement, only limited improvement of numerical results can be achieved. A possible means of further improvement might be in turbulence modelling.

In 2011, a numerical research project about the modelling of axial turbines was carried out at Turboinštitut [9]. Its purpose was to determine the optimal setup of a numerical model, which would be capable of reproducing the measured overall efficiency curve. The study was focused on the effect of hub and tip clearance, on the mesh refinement effect, effect of two- or seven- equation RANS turbulence models, and type of simulation (steady-state or transient). None of the results were satisfactory. Therefore, it was concluded that the only way to predict efficiency accurately at all operating regimes was to use advanced turbulence models, such as the scaleadaptive-simulation SST turbulence model (SAS SST), and zonal large eddy simulation (ZLES). The improvement of the results by these two turbulence models was presented in [2]. Such an analysis is too time-consuming to be used in the design process, but at least for the final geometry it is worth doing.

In this paper the results are presented for the same Kaplan turbine as in [2]. While the paper [2] was focused on comparison of predicted turbine efficiency to the measured values, in this paper also the values of discharge, torque and losses obtained by different turbulence models are compared to each other and to the measurements. The effects of different discretisation schemes for advection term and of grid density are also presented.

Numerical simulations were performed with the Ansys CFX solver [10].

\section{TURBULENCE MODELS AND DISCRETISATION SCHEMES}

In this paper, several turbulence models were used. Most of them are well known RANS turbulence models, such as the standard $k-\varepsilon$ turbulence model, the Wilcox $k-\omega$ model [11], the Baseline (BSL) $k-\omega$ model [12], the SST model [12] and [13] and the $\varepsilon$-based SSG RSM [14]. We have used two scaleresolving simulation (SRS) models, the SAS SST and the ZLES model.

The SAS SST turbulence model [15] is a socalled second generation URANS model, according to classification [16]. The model is essentially the SST turbulence model with an additional source term $Q_{\mathrm{SAS}}$ in the $\omega$ transport equation [17]:

$$
Q_{\mathrm{SAS}}=\max \left[f\left(\frac{L}{L_{\mathrm{vK}}}\right), 0\right] .
$$

The term $Q_{\mathrm{SAS}}$ can detect the unsteadiness of the solution through the comparison of the RANS length scale $L$ to the von Karman length scale $L_{\mathrm{vK}}$. The result of the unsteadiness is an increased value of $Q_{\mathrm{SAS}}$, which results in decreased turbulent viscosity. Consequently, the SAS SST develops an LES-like solution in unsteady regions. At the same time, the model provides standard RANS capabilities in stable flow regions. If the time step size is too large the unsteady structures can't be resolved and the model obtains an RANS or URANS solution [18].

The main idea of the ZLES model [17] is to resolve the flow inside a predefined zone with the LES model, and the rest of the domain with the RANS model. In CFX, the model source term in the $k$-equation forces the eddy viscosity to be equal to the LES subgrid-scale viscosity inside the user-specified zone. The synthetic turbulence at the RANS-LES boundary is based on harmonic flow generator [19] acting through a special source term in the momentum equation. In CFX, the ZLES model is available with all $k-\omega$ turbulence models (Wilcox, BSL, SST, BSL, explicit algebraic RSM, DES SST and SAS SST). In the presented simulations, the zone of the ZLES model was defined within the SAS SST simulation. The zone started just after the interface between the runner and the draft tube, and it is extended to the outlet of the computational domain.

Some turbulence models were used in combination with curvature correction (CC) [20] and with the Kato-Launder limiter (KL) [21] of turbulence production. The CC option captures the effects of streamline curvature and system rotation. When the $\mathrm{CC}$ option is selected, the production terms in $k$ and $\omega$ transport equations are multiplied by the upwards and downwards limited curvature correction function [20]. The function is defined as: 


$$
f_{\mathrm{rot}}=\left(1+c_{\mathrm{r} 1}\right) \frac{2 r^{*}}{1+r^{*}}\left[1-c_{\mathrm{r} 3} \tan ^{-1}\left(c_{\mathrm{r} 2} \hat{r}\right)\right]-c_{\mathrm{r} 1},
$$

where the $r^{*}$ and $\hat{r}$ are functions of the strain rate tensor $S_{i j}$ and of the effective rotation rate tensor $W_{i j}$, which includes the term of the system rotation

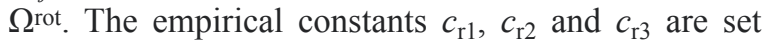
equal to 1,2 and 1 , respectively. The lower limit of the function is 0 , which represents strong convex curvature, whereas the upper limit is 1.25 , which represents strong concave curvature.

The KL limiter uses a different formulation to deal with the excessive production of turbulence energy at stagnation points, than it is the default in CFX. In CFX, the limiter is defined as a constant, multiplied by the density and the turbulence eddy dissipation. The KL limiter replaces one of the strain rates in the production term with the magnitude of vorticity [10] and [21].

In the simulations, we used either 'high resolution' or the bounded central difference scheme. The highresolution scheme (HRS) is a bounded second order upwind biased discretisation. The scheme calculates the bounded values based on the procedure of the Barth and Jespersen's scheme [22] and [23]. The bounded central difference scheme (BCDS) is based on the normalised variable diagram and blends from the central difference scheme (CDS) to the first-order upwind scheme when the convection boundedness criterion [24] is violated.

For convenience, short labels are used for turbulence models and discretisation schemes: SST for the Shear Stress Transport model, SAS for the SAS SST model, ZLES for the SAS SST ZLES model. So, for example, ZLES BCDS means the SAS SST ZLES turbulence model with BCDS used for the advection term.

\section{NUMERICAL PREDICTION OF FLOW AND ENERGETIC CHARACTERISTICS}

In this paper the results of a detailed numerical analysis of flow in a 6-blade Kaplan turbine which operates at middle head $(\psi=0.44)$ are presented. The model of the turbine was tested on a test rig in accordance with international standard IEC 60193 [25], so we were able to compare the numerical results with the measured ones. Numerical simulations were done for three angles of runner blades at constant head.

The turbine consists of semi-spiral casing with two vertical piers, 11 stay vanes and a nose, 28 guide vanes, a 6-blade runner and an elbow draft tube with two vertical piers. Tip clearance was modelled while hub clearance was neglected. The grid in the spiral casing with stay vanes was unstructured, while the grids in the other turbine parts were structured. All the grids satisfied the recommendations for orthogonality and the aspect ratio of elements. Near the walls the grids were refined to get recommended values of $\mathrm{y}^{+}$. For the draft tube and the draft tube prolongation, basic and refined grids were used. For the other turbine parts, our previous studies [9] showed that with proper values of $\mathrm{y}^{+}$, the number of nodes used in this case (see Table 1) is sufficient, and that by additional grid refinement only a negligible improvement of results can be obtained. The computational grid for the complete computational domain can be seen in Fig. 1.

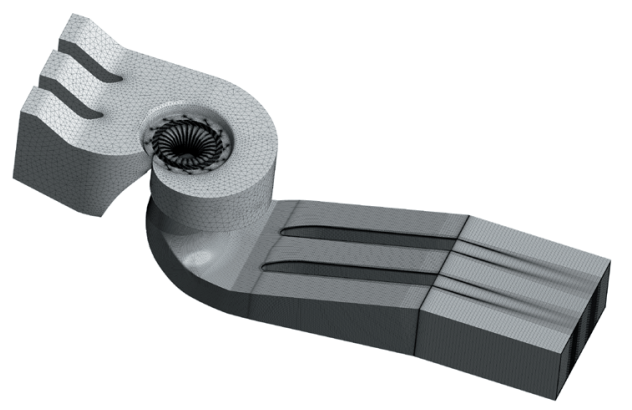

Fig. 1. Computational domain and basic grid

Table 1. Number of nodes for all turbine parts (in basic grid - BG and in fine grid - FG)

\begin{tabular}{lc}
\hline Turbine part & Number of nodes \\
\hline Semi spiral casing with stay vanes & $1,480,999$ \\
\hline Guide vane cascade & $2,755,496$ \\
\hline Runner & $1,858,374$ \\
\hline Draft tube (BG) & $1,786,432$ \\
\hline Draft tube prolongation (BG) & 398,056 \\
\hline Draft tube (FG) & $6,169,935$ \\
\hline Draft tube prolongation (FG) & $1,681,992$ \\
\hline Total (BG) & $8,279,357$ \\
\hline Total (FG) & $13,946,796$ \\
\hline
\end{tabular}

The numerical analysis was done in three stages. Firstly, a steady-state analysis at the local best efficiency points for three angles of runner blades was performed with several turbulence models. Secondly, a transient analysis was done with three turbulence models using two discretisation schemes (SST HRS, SAS HRS, SAS BCDS and ZLES BCDS) at only one operating point. Finally, a transient analysis was performed at several operating points for three angles of runner blades, with the ZLES turbulence model and BCDS. 


\subsection{Steady-State Analysis with Different Turbulence Models}

Steady-state analysis was performed on the basic grid with $k-\varepsilon, k-\omega$, BSL, SST and SSG-RSM turbulence models. For two-equation RANS models, simulations were repeated with $\mathrm{CC}$ and $\mathrm{KL}$ limiter of production term. For the $k-\varepsilon$ and SSG RSM models, scalable wall functions were used. For $k-\omega$ based turbulence models, automatic near-wall treatment was used. The automatic treatment allows a gradual switch between wall functions and the low-Reynolds number method. For discretisation of the advection term, the HRS implemented in ANSYS-CFX was used.

In the case of the SST CC KL and the SSG RSM turbulence models, three partial efficiency curves were simulated (see Section 2.3). In the other cases,

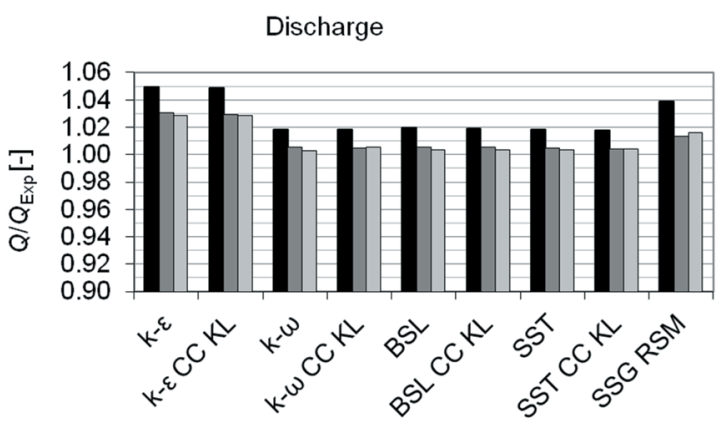

Flow energy losses before the runner

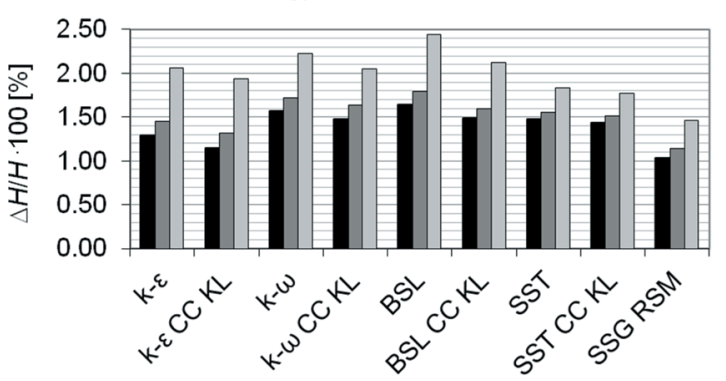

Flow energy losses in the draft tube

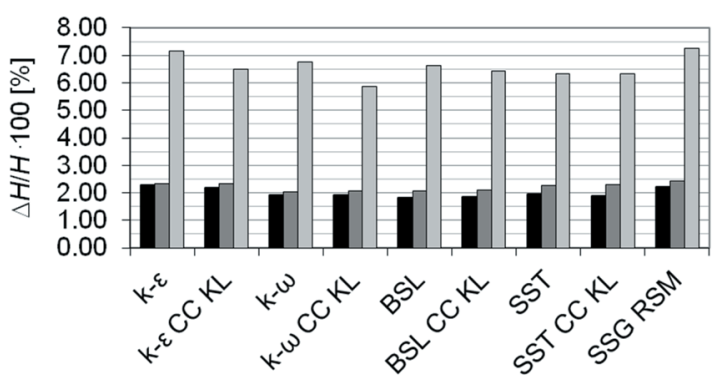

only analysis at the local best efficiency points for three angles of runner blades (see Table 2) was performed, with guide vane opening being determined from experimental data.

Table 2. Operating points for steady state analysis by different turbulence models

\begin{tabular}{cccc}
\hline Operating point & $\beta\left[^{\circ}\right]$ & $\varphi / \varphi_{\text {BEP }}$ & $\psi / \psi_{\text {BEP }}$ \\
\hline OP1 & 12 & 0.64 & 0.86 \\
\hline OP2 & 20 & 0.95 & 0.86 \\
\hline OP3 & 28 & 1.31 & 0.86 \\
\hline
\end{tabular}

The simulations were done at constant head and rotational speed. From numerical results the values of discharge, torque on the shaft, flow energy losses in all turbine parts and turbine efficiency, were obtained.
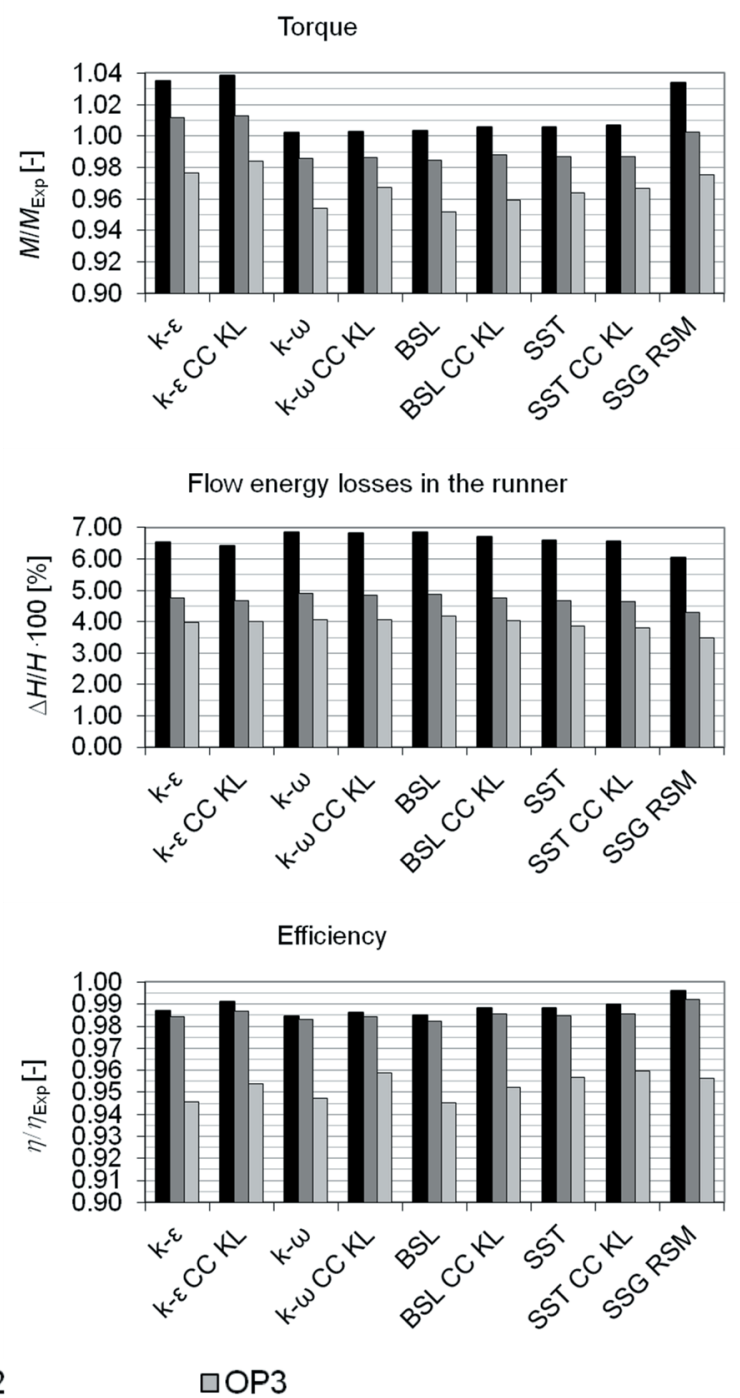

Fig. 2. Comparison between steady-state results obtained with different turbulence models and the measured values 
The results at local best efficiency points for each blade angle are presented in Fig. 2. The values of discharge, torque on the shaft and efficiency were divided by measured values at the same operating points. That means that all measured values in relative form are equal to 1 and are therefore not presented in the diagrams. The values of flow energy losses are presented in percentage of head.

For all operating points and all turbulence models, the calculated values of discharge were larger than the measured ones (relative values are larger than $1)$. The discrepancy was the largest when turbulence models $k-\varepsilon, k-\varepsilon$ CC KL and SSG RSM were used. Consequently, these three models gave the largest values of torque on the shaft. At OP1, calculated values of torque were too large when $k-\varepsilon, k-\varepsilon \mathrm{CC} \mathrm{KL}$ and SSG RSM models were used, while for the other models the values were very close to the measured ones.

At OP2, turbulence models $k-\varepsilon, k-\varepsilon$ CC KL and SSG RSM gave larger values of torque while all the other models gave smaller values than the measurements. At OP3 all models obtained too small values of torque.

For flow energy losses before the runner, in the runner and in the draft tube no measured values were available, so only the values obtained by different turbulence models can be compared with each other. For all turbulence models the values of losses before the runner, in the runner and in the draft tube decreased by using the KL limiter of production term and the $\mathrm{CC}$. The KL reduces flow energy losses at stagnation points, therefore its effect was significant in stay and guide vane cascades, and to a smaller degree also in the runner. Curvature correction acted mostly in the draft tube, where it reduced flow energy losses, especially for large discharge. When SSG RSM was used, flow energy losses before the runner and in the runner were smaller than those obtained by two equation models. The difference in losses before the runner obtained by the SST CC KL and SSG RSM models was between 0.3 and $0.4 \%$ of head at all three operating points. The differences in losses in the runner obtained by SST CC KL and SSG RSM were at OP1, OP2 and OP3; equal to $0.5,0.35$ and $0.31 \%$ of head, respectively. The losses in the draft tube, predicted by the SSG RSM model, were at OP1 slightly larger, at OP2 approximately the same and at OP3 significantly larger than those obtained by two-equation models with $\mathrm{KL}$ and $\mathrm{CC}$, the difference between SST CC KL and the SSG RSM at OP3 was about $0.95 \%$ of head.
Calculated efficiency values at all three operating points and for all turbulence models were smaller than the measured ones (relative values are smaller than 1). For all two-equation models the values of efficiency increased by using $\mathrm{KL}$ and $\mathrm{CC}$, due to smaller flow losses. At OP1 and OP2 all turbulence models predicted the efficiency values rather well. At OP1 the differences between measured efficiency and those obtained by SSG RSM and by SST CC KL were 0.38 and $1 \%$, respectively. The same differences at OP2 were 0.8 and $1.43 \%$. At OP3, the discrepancy between calculated and measured efficiency values was very large, for some of the two-equation models without $\mathrm{CC}$ and KL even more than 5\%. The agreement between measured and numerical results was the best when the SST CC KL or SSG RSM models were used, but the discrepancies were still 4 and $4.4 \%$, respectively.

\subsection{Transient Flow Simulation with Different Turbulence Models at One Operating Point}

We tried to improve the results by transient analysis. Three turbulence models were used in this respect: SST, SAS and ZLES. In the case of the SST turbulence model, the HRS was used for the advection term. The simulation by the SAS model was done firstly with BCDS and then also with a HRS, in order to see the influence of a discretisation scheme. In the case of the ZLES model, the BCDS was used. For time discretisation, a second order backward Euler scheme was used.

In order to reduce computational time, the domain for this analysis was without the spiral casing and stay vane cascade. For the draft tube and draft tube prolongation, refined grids were used (see Table 1). For an appropriate comparison of results the steadystate simulation with the SST model was repeated on the fine grid. In order to see the effect of grid density on results, a simulation with ZLES BCDS was performed on both grids, the basic and the fine one.

The inlet boundary and initial conditions were prescribed from the steady-state solution of the SST model. The velocity components were prescribed at the inlet boundary (at guide vane inlet), which means that the value of discharge was prescribed while the value of head was a result of the simulation. Time step size corresponded to 0.5 degrees of runner revolution. The average value of Courant number was, in all turbine parts, less than 0.3 , in the draft tube even less than 0.02 . Total simulation time corresponded to 30 runner revolutions. Transient analysis is very time consuming, therefore it was done only at one operating point for the blade angle of 28 degrees. This 
operating point is not the local best efficiency point. Its guide vane opening and discharge are smaller. The numerical analysis had started before the measured results were available, and the exact positions of the local best efficiency points had not been known yet.

In the case of transient simulations, a certain amount of time is required for the oscillating values of head, torque and efficiency to stabilise around average values. A detailed analysis of the results presented in [2] had showed that turbulent structures in the flow were after 10 runner revolutions not entirely developed, therefore the simulation time was extended to 30 runner revolutions. The results of the last ten runner revolutions were used to obtain averaged values of torque, head and efficiency.

In Fig. 3 a comparison of flow in the draft tube obtained by four simulations (steady-state SST, transient SST, SAS and ZLES) is presented. In the case of steady-state analysis by SST model there is a large swirl at the end of the cone, which with transient simulations nearly disappeared. Streamlines obtained with the SAS and the ZLES models are more curled than those obtained with SST. For the SAS model, the difference in flow due to the discretisation scheme was hardly visible, therefore only the results of SAS BCDS are illustrated. For ZLES, a coarser grid in the draft tube had a very small influence on streamlines, therefore this picture is also omitted. Turbulent structure in the flow can be better seen by the isosurface of velocity invariant Q (see Fig. 4), coloured by viscosity ratio (ratio between eddy and dynamic viscosity). With the steady-state SST and also by the transient SST model, only large structures in the flow were obtained, but with SAS and especially ZLES, also small turbulent structures in the flow were well resolved. Besides, it can be seen that values of viscosity ratio are large in the case of the SST model, and much smaller when the SAS and especially the ZLES models were used (see Table 3). While the influence of discretisation scheme in the case of SAS can hardly be seen, the grid density in the case of ZLES did have an effect on the size of turbulent structures and also on the value of viscosity ratio. Small turbulent structures in the flow can be obtained only on a fine grid where also the values of viscosity ratio are smaller.

In Fig. 5, the results of steady-state analysis (SST HRS) and of transient simulations (SST HRS, SAS HRS, SAS BCDS, ZLES BCDS) are presented. The values of head, torque and efficiency were divided by the measured values. The flow energy losses were divided by the measured value of head. The value of discharge was the input data and it was equal for all simulations.

Table 3. The values of viscosity ratio in the draft tube

\begin{tabular}{lcc}
\hline Numerical modeling and & \multicolumn{2}{c}{ Eddy viscosity / Dynamic viscosity } \\
\cline { 2 - 3 } grid density & maximal & averaged \\
\hline Steady-state SST HRS, FG & 10152 & 2527 \\
\hline Transient SST HRS, FG & 6005 & 1439 \\
\hline SAS HRS, FG & 1146 & 169 \\
\hline SAS BCDS, FG & 1311 & 180 \\
\hline ZLES CDS, FG & 850 & 81 \\
\hline ZLES CDS, BG & 1020 & 95 \\
\hline
\end{tabular}

The spiral casing with stay vanes was not included in the computational domain, therefore the flow energy losses before the runner were calculated as a sum of the losses in a guide vane cascade obtained by transient simulation, and the losses in the spiral casing obtained by the previous steady-state analysis. It can be seen that the losses before the runner are nearly the same in all cases.

In the runner, the highest losses were obtained with steady-state, and transient analysis with the SST HRS (3.81 and 3.93\%, respectively) and the smallest with SAS BCDS (3.41\%) and ZLES BCDS (3.51\%). Losses in the runner obtained by SAS HRS $(3.74 \%)$ are closer to the losses of steady-state and transient SST HRS than to SAS BCDS.

Flow energy losses in the draft tube differ significantly due to steady-state or transient analysis and due to the choice of a turbulence model and discretisation scheme. In the case of steady-state analysis by SST HRS, the losses in the draft tube exceed $6.6 \%$ of turbine head, while in case of transient analysis with the same model they reduce to $3.47 \%$. The losses obtained with SAS HRS, SAS BCDS and ZLES BCDS are 2.93, 3.0 and $2.94 \%$, respectively.

Steady-state simulation with SST HRS underestimated the value of torque on the shaft by $5.07 \%$. With transient simulations the prediction of torque improved significantly. Transient SST HRS and SAS HRS underestimated values of torque by 0.78 and $0.71 \%$, respectively. SAS BCDS and ZLES BCDS overrated torque by 0.039 and $0.036 \%$, respectively. It seems that for torque prediction a choice of differential scheme for advection term was more important than the choice of turbulence model. When HRS was used, SST and SAS predicted nearly the same values of torque. Similarly, when BCDS was used, SAS and ZLES predicted nearly the same value. On the other hand, the difference between values obtained with SAS HRS and SAS BCDS is significant in spite of the same turbulence model. It is likely 


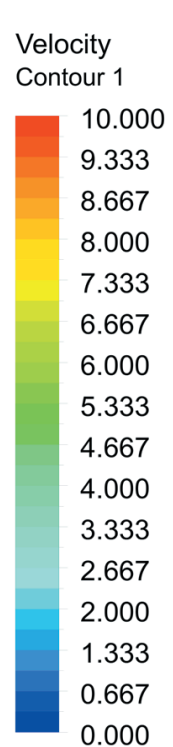

$[\mathrm{m} \mathrm{s}-1]$
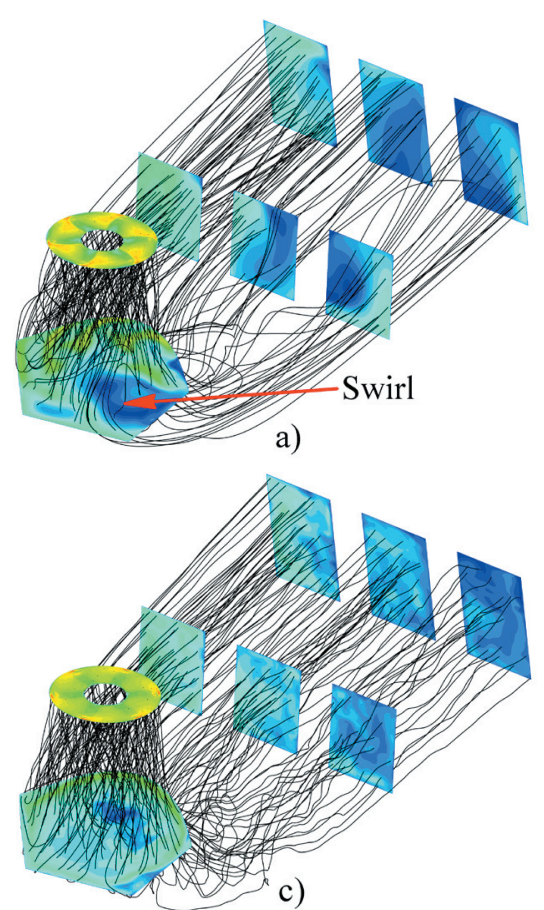

c)

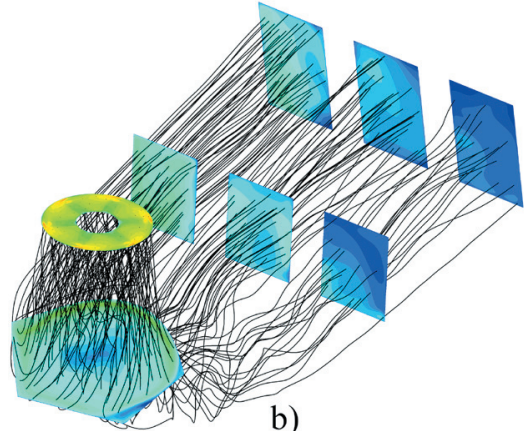

b)

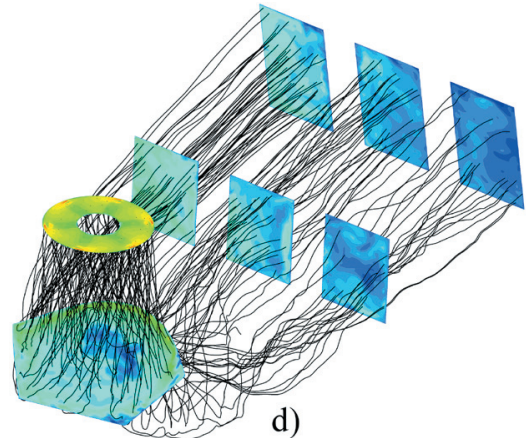

Fig. 3. Streamlines and velocity contours in the draft tube; a) steady-state SST, HRS, FG, b) transient SST, HRS, FG, c) SAS, BCDS, FG, and d) ZLES, BCDS, FG
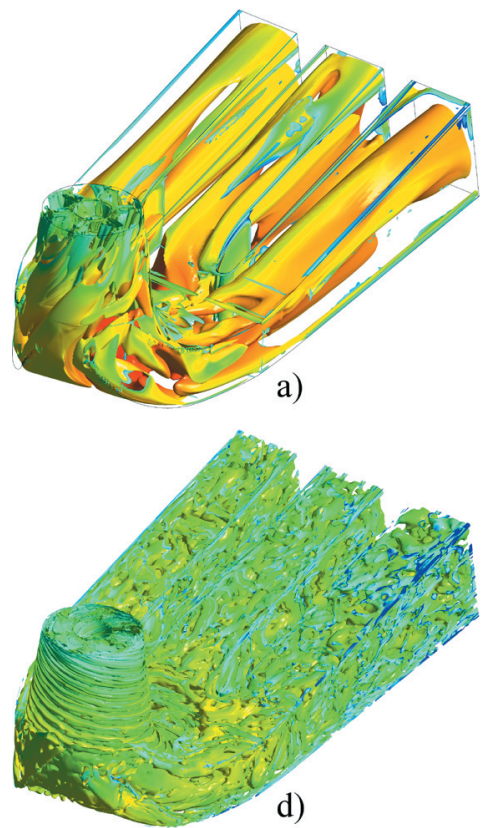
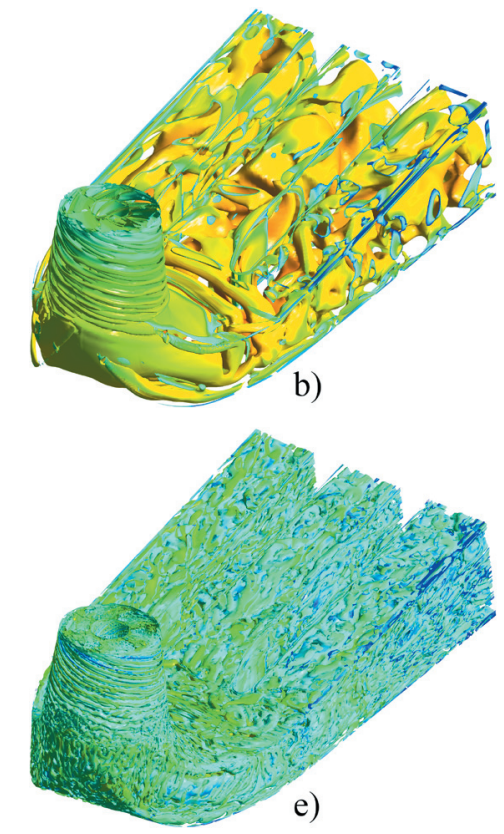

Viscosity Ratio

Fig. 4. Isosurfaces of velocity invariant $Q=0$; a) steady-state $S S T, H R S, F G, b)$ transient $S S T, H R S, F G, c) S A S, H R S, F G$, d) $S A S, B C D S, F G$, e) ZLES, BCDS, FG, and f) ZLES, BCDS, BG

that in the runner the $Q_{\mathrm{SAS}}$ term was less important because close to the runner surface the SAS model acted as the SST model. On the contrary, the choice
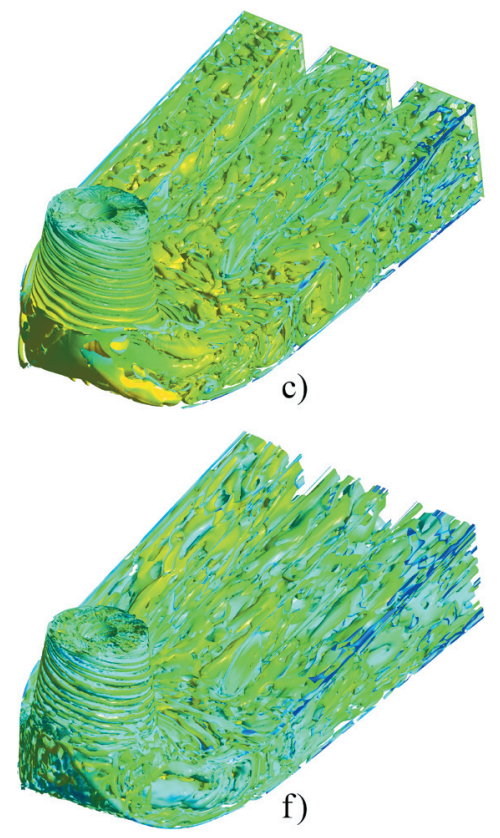

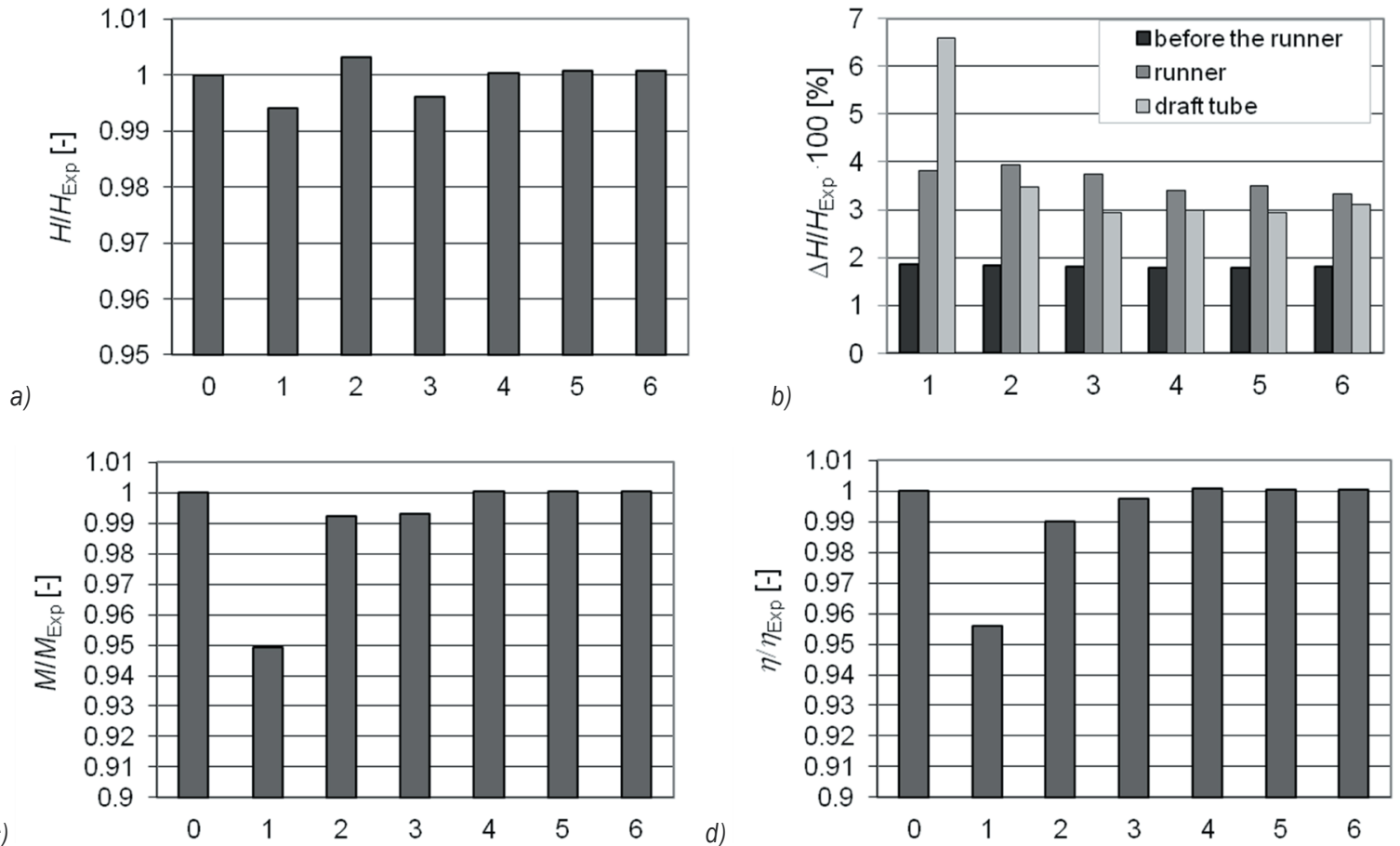

C)

b)

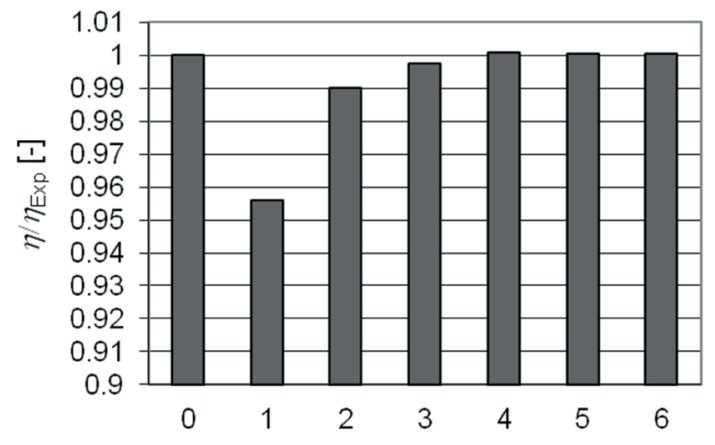

0 = measurement; 1 = steady-state SST, HRS, FG; 2 = transient SST, HRS, FG;

3 =SAS, HRS, FG; 4 = SAS, BCDS, FG; 5 = ZLES, BCDS, FG; 6 = ZLES, BCDS, BG

Fig. 5. Comparison of results obtained with different turbulence models to the measurements of a) head, b) flow energy losses, c) torque, d) efficiency

The values of calculated efficiency differ mostly due to different values of flow energy losses in the draft tube and different values of torque. The efficiency value calculated from steady-state solution with SST HRS was $4.42 \%$ smaller than the measured one. With transient analysis the results improved significantly. With SST HRS and SAS HRS the efficiency values were smaller than the measured ones by 1.01 and $0.24 \%$. The agreement between measured and numerical values is excellent for SAS BCDS and ZLES BCDS, where the discrepancy is 0.09 and $0.05 \%$, respectively. Based on the results it can be concluded that the SAS and ZLES models with BCDS are very suitable for flow simulation at operating points with large discharge. Results obtained by SAS HRS are less accurate mostly due to underestimated torque.

Comparing the results of ZLES BCDS on fine and basic grids it was seen that the effect of grid density on the calculated torque, head and efficiency was negligible. Flow energy losses in the draft tube were only higher by $0.18 \%$ of head, than on the fine grid. Therefore, for transient simulations for different operating regimes (Section 2.3) the basic grid was used.

\subsection{Transient Flow Simulation with the Zonal LES Model for Different Operating Regimes}

The purpose of this study is to find a turbulence model that would be capable of predicting efficiency accurately for all operating regimes (OP1, OP2 and OP3). In the previous section, the ZLES model (at operation regime close to OP3) showed such potential. In order to see whether this model is suitable for all operating regimes it should be thoroughly tested at several operating points for three angles of runner blades.

In this section, simulations with ZLES were performed for the whole turbine. To reduce computational time, basic grids for the draft tube and draft tube prolongation were used. In all transient simulations $\mathrm{CC}$ and $\mathrm{KL}$ are included. The input data consisted of geometry, head and rotational speed. The results were the values of discharge, torque on the shaft, flow energy losses and efficiency. 


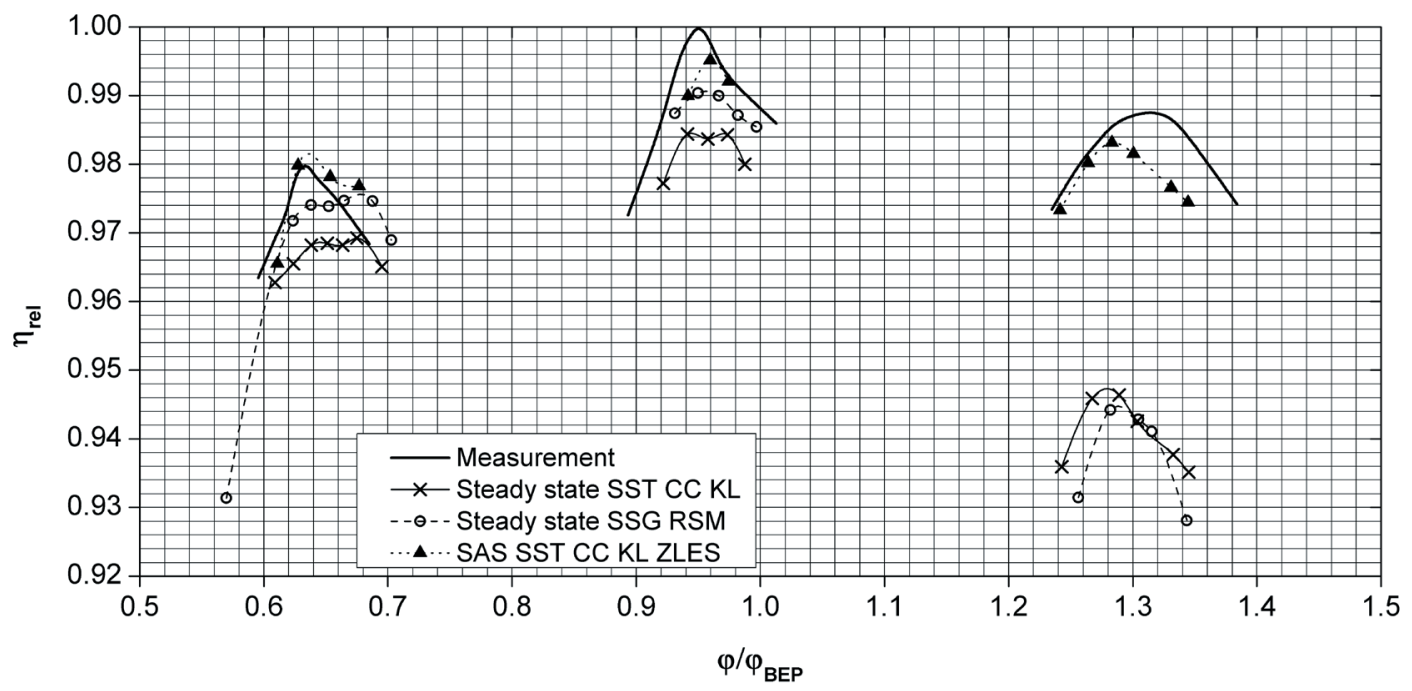

Fig. 6. Efficiency diagram - measurements and CFD

Table 4. Calculated flow energy losses in the draft tube. $\Delta H / H \times 100$ [\%]

\begin{tabular}{llll}
\hline Simulation type & OP1 & OP2 & OP3 \\
\hline Steady-state SST CC KL & 1.88 & 2.29 & 6.32 \\
\hline Steady-state SSG RSM & 2.22 & 2.43 & 7.26 \\
\hline SAS SST CC KL ZLES & 1.12 & 1.56 & 3.33 \\
\hline
\end{tabular}

The efficiency prediction is presented in Fig. 6. All values were divided by the measured efficiency at OP2. The diagram shows a clear distinction between the results of steady-state analysis and the results of the transient ones obtained with the ZLES model. With ZLES, the efficiency prediction was improved at all operating points, but the improvement was most significant for runner blade angle 28 degrees, where the decrease of calculated flow energy losses in the draft tube was the largest (see Table 4). At the local best efficiency point for runner blade angle 12 degrees (OP1), the calculated and measured values were practically the same. At OP2 (blade angle 20 degrees), the efficiency value obtained with ZLES was about $0.5 \%$ smaller than the measured one. In the section 2.2 for blade angle 28 degrees, the discrepancy in efficiency was only $0.05 \%$. That operating point corresponded to the third point from the left on the ZLES curve for 28 degrees In Fig. 6 the efficiency values at the first three points on the ZLES curve for blade angle 28 degrees agreed with the measured results well. At higher discharge, the discrepancy increased. Peak to peak difference in efficiency values was $0.44 \%$ but numerically obtained position of the local best efficiency point was shifted to the left. The tendency that numerical prediction is less accurate at operating points with large discharge still remains, but the improvement with the ZLES model was significant.

\section{COMPUTATIONAL EFFORT}

Transient numerical simulations are very time consuming. To get reliable results the grids have to be refined enough and time step must not be too large to get proper values of Courant number. Besides, it takes a long time before the values of efficiency stabilise. Usually more than 20 runner revolutions are needed to get stable values.

The simulations were run on a supercomputer cluster with 512 Quad-Core Intel Xeon processors L5335. For the simulation on the basic grid (8.3 million nodes) with the ZLES model, 8 quad-core processors (64 cores) were used and the computational time was about 28 hours for one runner revolution.

Too long CPU time is the main disadvantage of transient simulations and the reason for their limited use in the design process. It can be expected that with future development of hardware and software the problem will be overcome.

\section{CONCLUSIONS}

- Steady-state analysis failed entirely to predict flow in the Kaplan turbine. Even for small and optimal runner blade angles, where efficiency was quite accurately predicted, a detailed analysis of results showed that the prediction of torque and discharge values (head as input data) was 
not accurate enough. At full rate the efficiency prediction was extremely poor. The discrepancy was more than $4 \%$, mostly due to underestimated torque on the shaft and overestimated flow energy losses in the draft tube. The results were only slightly improved by using the KL and CC.

- Transient simulations with SST HRS, SAS HRS, SAS BCDS and ZLES BCDS were performed at one operating point for a maximal runner blade angle. The results were significantly improved. The largest improvement was achieved with SAS BCDS and ZLES BCDS, where not only the efficiency values but also the values of torque and head (discharge as input data) were almost equal to the measured values.

- Comparing transient results of SST HRS, SAS HRS and SAS BCDS, it can be concluded that the improvement due to the use of BCDS instead of HRS, was even larger than the improvement due to the use of SAS instead of SST. With BCDS, the agreement with measurements was improved mostly because of smaller losses in the runner and better prediction of torque on the shaft.

- The effect of grid refinement in the draft tube, on efficiency prediction with ZLES BCDS, was negligible in spite of clearly seen differences in vortex structures. A grid with about 2 million nodes was in this case fine enough for reliable results.

- It is important that transient simulations are not stopped too soon, otherwise swirls from the steady-state simulations used as initial conditions still remain, and also vortex structures are not entirely developed.

- Simulations with ZLES BCDS were performed at several operating points for three runner blade angles. The discrepancy in efficiency values was smaller than $1 \%$ at all operating points. It can be concluded that ZLES model with BCDS is suitable for all operating regimes.

\section{ACKNOWLEDGEMENTS}

The authors are grateful to their colleagues and especially to the head of the Turbine R\&D Department, Dr. Vesko Djelić, for geometrical data and measured results. The research was partially funded by the Slovenian Research Agency ARRS - Contracts No. P2-0196 and 1000-09-160263.

\section{NOMENCLATURE}

\begin{tabular}{|c|c|c|}
\hline \multicolumn{2}{|c|}{$c_{\mathrm{r} 1}, c_{\mathrm{r} 2}, c_{\mathrm{r} 3}[-]$} & Empirical constants for $f_{\text {rot }}$ \\
\hline$f_{\text {rot }}$ & {$[-]$} & Curvature correction function \\
\hline$g$ & {$\left[\mathrm{~m} \cdot \mathrm{s}^{-2}\right]$} & Gravitation \\
\hline$H$ & [m] & Head \\
\hline$H_{\text {Exp }}$ & {$[\mathrm{m}]$} & Head, experimental value \\
\hline$\Delta H$ & {$[\mathrm{~m}]$} & $\begin{array}{l}\text { Flow energy losses } \\
\Delta H=\Delta P_{\text {tot }} /(\rho g)\end{array}$ \\
\hline$k$ & {$\left[\mathrm{~m}^{2} \cdot \mathrm{s}^{-2}\right]$} & $\begin{array}{l}\text { Turbulence kinetic energy per } \\
\text { unit mass }\end{array}$ \\
\hline$L$ & {$[\mathrm{~m}]$} & RANS length scale \\
\hline$L_{\mathrm{vK}}$ & [m] & Von Karman length scale \\
\hline$M$ & {$[\mathrm{Nm}]$} & Torque on the shaft \\
\hline$M_{\text {Exp }}$ & {$[\mathrm{Nm}]$} & $\begin{array}{l}\text { Torque on the shaft, } \\
\text { experimental value }\end{array}$ \\
\hline$P_{\text {tot }}$ & {$\left[\mathrm{Nm}^{-2}\right]$} & Total pressure \\
\hline$Q$ & {$\left[\mathrm{~m}^{3} \mathrm{~s}^{-1}\right]$} & Discharge \\
\hline$Q_{\mathrm{SAS}}$ & {$\left[\mathrm{kg} \cdot \mathrm{m}^{-3} \cdot \mathrm{s}^{-2}\right.$} & $\begin{array}{l}\text { Source term in } \omega \text {-equation for } \\
\text { the SAS SST model }\end{array}$ \\
\hline$r$ & {$[\mathrm{~m}]$} & Runner radius \\
\hline$\hat{r}, r^{*}$ & {$[-]$} & $\begin{array}{l}\text { Non-dimensional arguments } \\
\text { in } f_{\text {rot }}\end{array}$ \\
\hline$\beta$ & [degrees] & Runner blade angle \\
\hline$\varepsilon$ & {$\left[\mathrm{m}^{2} \mathrm{~s}^{-3}\right]$} & Turbulence dissipation rate \\
\hline$\eta$ & {$[-]$} & Efficiency \\
\hline$\eta_{\text {Exp }}$ & {$[-]$} & Efficiency, experimental value \\
\hline$\eta_{\mathrm{rel}}$ & {$[-]$} & $\begin{array}{l}\text { Efficiency divided by } \\
\text { measured efficiency at OP2 }\end{array}$ \\
\hline$\varphi$ & {$[-]$} & $\begin{array}{l}\text { Discharge coefficient } \\
\varphi=Q /\left(\pi \omega r^{3}\right)\end{array}$ \\
\hline$\rho$ & {$\left[\mathrm{kg} \mathrm{m}^{-3}\right]$} & Density \\
\hline$\psi$ & {$[-]$} & $\begin{array}{l}\text { Energy coefficient } \\
\psi=2 g H /(\omega r)^{2}\end{array}$ \\
\hline$\omega$ & {$\left[\mathrm{s}^{-1}\right]$} & Runner speed \\
\hline$\omega$ & {$\left[\mathrm{s}^{-1}\right]$} & Turbulence frequency \\
\hline
\end{tabular}

BCDS Bounded central differential scheme

BEP Best efficiency point

BG Basic grid

CC Curvature correction

FG Fine grid

HRS High resolution scheme

KL Kato-Launder limiter of production term in equation for turbulent kinetic energy

SAS Scale adaptive simulation

SST Shear stress transport

ZLES Zonal large eddy simulation 


\section{REFERENCES}

[1] Motycak, L., Skotak, A., Obrovsky, J. (2010). Analysis of the Kaplan draft tube effect. IOP Conference Series: Materials Science and Engineering, vol. 12, no. 1, p. 012038, DOI:10.1088/1755-1315/12/1/012038.

[2] Jošt, D., Škerlavaj, A., Lipej, A. (2012). Numerical flow simulation and efficiency prediction for axial turbines by advanced turbulence models. IOP Conference Series: Materials Science and Engineering, vol. 15, no. 6, p. 062016, DOI:10.1088/1755-1315/15/6/062016.

[3] Gebart, B.R., Gustavsson, L.H., Karlsson, R.I. (2000). Proceedings of Turbine-99 - Workshop on draft tube flow. Luleå University of Technology, Luleå.

[4] Cervantes, M.J., Engström, T.F., Gustavsson, L.H. (2005). Turbine-99 III. Luleå University of Technology, Luleå.

[5] Marjavaara, D., Kamakoti, R., Lundstöm, T.S., Siddharth, T., Wright, J., Schy, W. (2005). Steady and unsteady CFD simulations of the Turbine-99 draft tube CFX-5 and STREAM. Cervantes, M.J., Engström, T.F., Gustavsson, L.H. (eds.), Turbine-99 III. Luleå University of Technology, Luleå, p. 83-100.

[6] Kurosawa, S., Nakamura, K. (2005). Unsteady turbulent flow simulation in Turbine-99 draft tube. Cervantes, M.J., Engström, T.F., Gustavsson, L.H. (eds.), Turbine-99 III. Luleå University of Technology, Luleå, p. 73-82.

[7] Cervantes, M.J., Andersson, U., Lövgren, H.M. (2010). Turbine-99 unsteady simulations - Validation. IOP Conference Series: Materials Science and Engineering, vol. 12, no. 1, p. 012014, DOI:10.1088/17551315/12/1/012014.

[8] Nilsson, H., Cervantes, M.J. (2012). Effects of inlet boundary conditions on the computed flow in the Turbine-99 draft tube, using OpenFOAM and CFX. IOP Conference Series: Materials Science and Engineering, vol. 15, no. 3, p. 032002, DOI:10.1088/17551315/15/3/032002.

[9] Jošt, D., Drešar, P. (2011). Numerical Analysis of the Flow in an Axial Turbine by Different Turbulence Models, Report Nr. 3046. Turboinštitut, Ljubljana (in Slovene).

[10] ANSYS (2012). ANSYS CFX-Solver Theory Guide. Ansys, Canonsburg.

[11] Wilcox, D.C. (1994). Turbulence Modelling for CFD. DCW Industries, La Cañada.

[12] Menter, F.R. (1994). Two-equation eddy-viscosity turbulence models for engineering applications. AIAA Journal, vol. 32, no. 8, p. 1598-1605, DOI:10.2514/3.12149.

[13] Menter, F.R., Kuntz, M., Langtry, R. (2003). Ten years of industrial experience with the SST turbulence model. Hanjalić, K., Nagano, Y., Tummers, M. (eds.), Turbulence, Heat and Mass Transfer 4. Begell House, New York, p. 625-632.

[14] Speziale, C.G., Sarkar, S., Gatski, T.B. (1991). Modelling the pressure-strain correlation of turbulence: an invariant dynamical systems approach. Journal of Fluid Mechanics, vol. 277, no. 1, p. 245-272, DOI:10.1017/S0022112091000101.

[15] Egorov, Y., Menter, F. (2008). Development and application of SST-SAS turbulence model in the DESIDER project. Peng, S.-H., Haase, W. (eds.), Advances in Hybrid RANS-LES Modelling. Springer, Heidelberg, p. 261-270, DOI:10.1007/978-3-54077815-8_27.

[16] Fröhlich, J., Terzi, D. (2008). Hybrid LES/RANS methods for the simulation of turbulent flows. Progress in Aerospace Sciences, vol. 44, no. 1, p. 349-377, DOI:10.1016/j.paerosci.2008.05.001.

[17] Menter, F.R., Gabaruk, A., Smirnov, P., Cokljat, D., Mathey, F. (2010). Scale-Adaptive Simulation with Artificial Forcing. Peng, S.-H., Doerffer, P., Haase, W. (eds.), Progress in Hybrid RANS-LES Modelling. Springer, Berlin, p. 235-246, DOI:10.1007/978-3-64214168-3_20.

[18] Menter, F., Egorov, Y. (2009). Formulation of the Scale-Adaptive Simulation (SAS) Model during the DESIDER Project. Haase, W., Braza, M., Revell, A. (eds.), DESider - A European Effort on Hybrid RANS-LES Modelling. Springer, Berlin, p. 51-62, DOI:10.1007/978-3-540-92773-0.

[19] Adamian, D., Travin, A. (2011). An efficient generator of synthetic turbulence at RANS-LES interface in embedded LES of wall-bounded and free shear flows. Kuzmin, A. (ed.), Computational Fluid Dynamics 2010. Springer, Berlin, p. 739-744, DOI:10.1007/9783-642-17884-9.

[20] Smirnov, P.E., Menter, F. (2009). Sensitization of the SST turbulence model to rotation and curvature by applying the Spalart-Shur correction term. Journal of Turbomachinery, vol. 131, no. 4, p. 041010, DOI:10.1115/1.3070573.

[21] Kato, M., Launder, B.E. (1993). The modelling of turbulent flow around stationary and vibrating square cylinders. Proceedings of the 9th Symposium on Turbulent Shear Flows, p. 10.4.1-10.4.6.

[22] Barth, T.J., Jespersen, D.C. (1989). The design and application of upwind schemes on unstructured meshes. 27th Aerospace Sciences Meeting, AIAA Paper 89-0366.

[23] Darwish, M.S., Moukalled, F. (2003). TVD schemes for unstructured grids. International Journal of Heat and Mass Transfer, vol. 46, no. 4, p. 599-611, DOI: 10.1016/S0017-9310(02)00330-7.

[24] Jasak, H., Weller, H.G., Gosman, A.D. (1999). High resolution NVD differencing scheme for arbitrarily unstructured meshes. International Journal for Numerical Methods in Fluids, vol. 31 , no. 2, p. 431-449, DOI:10.1002/(SICI)10970363(19990930)31:2<431::AID-FLD884>3.0.CO;2-T.

[25] IEC 60193 (1999). Hydraulic turbines, storage pumps and pump-turbine - Model acceptance tests. International Electrotechnical Commission, Geneva. 